\title{
Análise do Comportamento das Operações de Entrada e Saída de um Workflow Científico de Alto Desempenho
}

\author{
Lucas Cruz $^{1,2}$, Micaella Coelho ${ }^{2}$, Luiz Gadelha ${ }^{2}$, Carla Osthoff $^{2}$, Kary Ocaña $^{2}$ \\ ${ }^{1}$ Centro Federal de Educação Tecnológica Celso Suckow da Fonseca (CEFET/RJ) \\ Petrópolis - RJ - Brasil \\ ${ }^{2}$ Laboratório Nacional de Computação Científica (LNCC) \\ Petrópolis - RJ - Brasil \\ \{lucruz, micaella, lgadelha, osthoff, karyann\}@lncc.br
}

\begin{abstract}
We present an analysis of the behavior of the I/O operations of the scientific workflow version ParslRNA-Seq, coupled to HPC environments. The article discusses the choice of which workflow modeling modifications lead to improved performance and computational scalability, based on reduced expenses with I/O operations.
\end{abstract}

Resumo. Apresentamos uma análise do comportamento das operações de E/S da versão do workflow científico ParslRNA-Seq, acoplada a ambientes de CAD. $O$ artigo traz discussões sobre a eleição de quais modificações na modelagem do workflow levam a melhora do desempenho e escalabilidade computacional, baseado em redução de gastos em operações de E/S.

\section{Introdução}

A técnica de Sequenciamento de RNA (RNA-Seq) é utilizada nas análises de expressão de genes do transcritoma, para o estudo de um conjunto de transcritos de uma célula em uma dada condição fisiológica ou de desenvolvimento, como o câncer. Na bioinformática, a modelagem de experimentos de RNA-Seq é um desafio devido à complexidade, manipulação de grandes volumes de dados e pelo custo computacional. Workflows científicos são abstrações que representam esses experimentos como um fluxo encadeado de atividades as quais são executadas por aplicações com diversas características, dentre elas a de Computação de Alto Desempenho (CAD). Com o uso de sistemas de gerência ou linguagens de programação é possível modelar, gerenciar e analisar os workflows.

Este trabalho é uma extensão de [Cruz et al. 2021] o qual apresenta o workflow científico ParsIRNA-Seq, com desempenho validado por análises comparativas computacionais e de inferência em análises de Expressão Diferencial de Genes (EDG), no qual foi desenvolvida uma versão paralela e distribuída em múltiplos nós, com ganhos de desempenho em até $70 \%$. O presente trabalho apresenta análises do desempenho das operações de Entrada e Saída (E/S) deste mesmo workflow, em ambientes de CAD, com o objetivo de investigar a possibilidade de aumentar ainda mais o ganho de desempenho através da redução do tempo de execução com as operações de E/S.

\section{Trabalhos Relacionados}

[Cruz et al. 2020] apresenta análises de desempenho do ParslRNA-Seq_alfa executado no ambiente do supercomputador Santos Dumont (SDumont). As análises mostram que 
o gerenciamento do Parsl em conjunto com o parâmetro multithread do Bowtie2, levam a reduções significativas no Tempo Total de Execução (TTE) do workflow, saindo de cerca de 3 dias para, aproximadamente, 1 hora e 10 minutos. [Cruz et al. 2021] apresenta uma versão otimizada do ParslRNA-Seq, onde são observados ganhos de desempenho de até $70 \%$ em relação a versão alfa dentro de ambientes de CAD. Essa melhora reduziu o TTE do workflow de, aproximadamente, 1 hora e 10 minutos para cerca de 24 minutos.

\section{Metodologia}

O ParsIRNA-Seq é composto por seis atividades [Cruz et al. 2021]: A atividade 1, Bowtie, faz o mapeamento e comparação das leituras dos genomas, caractere a caractere, em arquivos extremamente extensos; A atividade 2, Sort, realiza uma ordenação nas leituras e converte o formato de saída do arquivo da atividade 1, para um formato binário comprimido; A atividade 3, Split_Picard, faz a manipulação para o particionamento das leituras, o que gera uma quantidade de $n$ subarquivos. A atividade 4, HTSeq, faz a contagem dessas leituras processando cada subarquivo em um núcleo de CPU; A atividade 5, Merge_HTSeq, combina as subsoluções geradas; e, por fim, a atividade 6, DESeq, aplica estatísticas de EDG sobre as contagens realizadas. Das seis atividades, as atividades $1 \mathrm{e}$ 2 fazem execução multithreads e a atividade 4, execução multicore.

Para a análise foi reproduzido o melhor cenário de execução observado nos trabalhos anteriores. O conjunto de dados de entrada utilizados contém ao todo seis arquivos, pertencentes a um experimento real de RNA-Seq, com tamanhos variando entre $1.8 \mathrm{~GB}$ e 3.0 GB. O ambiente computacional utilizado SDumont e foram alocados seis nós computacionais para execução do workflow, dos quais se compõem por duas CPUs Ivy Bridge Intel Xeon E5-2695v2 (12c @2.4GHz) e 64 GB de memória RAM. Para análise foi utilizado o perfilador Darshan, que tem como propósito investigar o comportamento de E/S de aplicações em ambientes de alto desempenho.

\section{Resultados e Análise}

$\mathrm{Na}$ presente seção, são discorridas análises das atividades que se apresentam de forma mais relevante em relação as operações de E/S: Bowtie e Sort. As análises levam em consideração o arquivo de menor e maior tamanho, 1.8 GB e 3.0 GB, respectivamente. A Figura 1 apresenta a média do custo das operações usando POSIX: de leitura (vermelho); de escrita (verde); e, outras operações que não envolvem E/S (rosa).

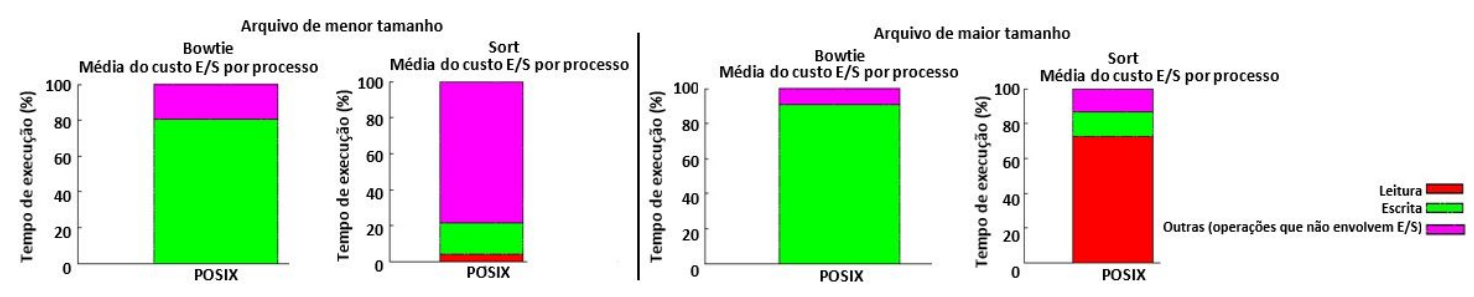

Figura 1. Atividades Bowtie e Sort: menor arquivo (esquerda) e maior (direita).

Análise das operações de E/S da atividade Bowtie. Para a atividade Bowtie as operações de escrita são as que mais se destacam. De modo que para o arquivo de maior tamanho, o TTE é cerca de 4 minutos e 23 segundos e cerca de $90 \%$ desse tempo é consumido em operações de escrita. Em média, a atividade escreveu 11 GB. Já para o 
arquivo de menor tamanho, o TTE é de 2 minutos e 32 segundos e cerca de $80 \%$ desse tempo é gasto para operações de escrita. Em média, a atividade escreveu 6.0 GB. O que se constata é que a operação principal dessa atividade é a escrita, dado a variação de $10 \%$ na porcentagem do tempo gasto para tal entre o maior e menor arquivo. Além disso, o tamanho dos blocos que essa aplicação usa para escrita variam entre $1 \mathrm{~KB}$ e $10 \mathrm{~KB}$.

Análise das operações de $\mathbf{E} / \mathbf{S}$ da atividade Sort. Para a atividade Sort as operações de escrita já não estão tão em destaque. De modo que para o arquivo de maior tamanho, o TTE é cerca de 1 minuto e 31 segundos e cerca de $70 \%$ desse tempo é consumido em operações de leitura e cerca de $10 \%$ em operações de escrita. Em média são lidos 13 GB e escritos 1.1 GB. Já o arquivo de menor tamanho, o TTE é de 41 segundos, cerca de $5 \%$ é consumido em operações de leitura e em torno de $15 \%$ em operações de escrita. Em média são lidos 7.3 GB e escritos $657 \mathrm{MB}$. O que se constata é que a medida que o tamanho do arquivo aumenta, maior será a quantidade e mais tempo será gasto realizando operações de leitura. Isso pode ocorrer devido ao tamanho do arquivo e ao tamanho de blocos que a atividade do Sort utiliza para leitura (de $100 \mathrm{~KB}$ a $1 \mathrm{MB}$ ) e escrita (1 MB a $4 \mathrm{MB}$ ), ou seja, como o tamanho de blocos de leitura são menores, quanto maior for o tamanho do arquivo mais blocos de leitura serão requeridos e maior será a quantidade de operações de leitura a serem realizadas.

\section{Conclusão}

A partir das análises do comportamento das operações de E/S das atividades Bowtie e Sort do workflow ParsIRNA-Seq, é notório uma relação entre o tamanho do arquivo de entrada e a quantidade de operações de E/S. Em geral, a atividade Bowtie consome mais tempo em escrita, no entanto, essa escrita é feita em blocos de tamanho $1 \mathrm{~KB}$ a $10 \mathrm{~KB}$, independentemente do tamanho do arquivo. O que pode influenciar no tempo de execução da atividade. Para a atividade Sort essa relação é bem mais perceptível, dado que há uma diferença de cerca de $65 \%$ no tempo gasto com operações de leitura entre maior e menor aquivo. E o tamanho dos blocos de leitura estão sempre dentro de uma faixa entre $100 \mathrm{~KB}$ e $1 \mathrm{MB}$, independentemente do tamanho do arquivo. Uma forma de reduzir o custo dessas operações de E/S é fazendo alteração no tamanho dos blocos, no entanto, é necessário realizar modificações dentro das próprias aplicações. Uma outra forma de reduzir gastos com E/S é realizando modificações na própria configuração de execução do workflow, para que as operações de E/S sejam feitas diretamente no SSD (Solid State Drive) do nó computacional em uso. Ambas abordagens fazem parte do próximos passos desse estudo.

\section{Referências}

Cruz, L., Coelho, M., Gadelha, L., Ocaña, K., and Osthoff, C. (2020). Avaliação de desempenho de um workflow científico para experimentos de rna-seq no supercomputador santos dumont. In Anais Estendidos do XXI Simpósio em Sistemas Computacionais de Alto Desempenho, pages 86-93, Porto Alegre, RS, Brasil. SBC.

Cruz, L., Coelho, M., Terra, R., Carvalho, D., Gadelha, L., Osthoff, C., and Ocaña, K. (2021). Workflows científicos de rna-seq em ambientes distribuídos de alto desempenho: Otimização de desempenho e análises de dados de expressão diferencial de genes. In Anais do XV Brazilian e-Science Workshop, pages 57-64, Porto Alegre, RS, Brasil. SBC.

Agradecemos ao LNCC/MCTI pelos recursos do SDumont e as agências de formento CNPq e FAPERJ. 